\title{
AC 2009-37: REVERSE CURRICULUM DESIGN OF LEAN MANUFACTURING FOR DISTANCE EDUCATION
}

\section{Chad Laux, Purdue University}

Dr. Chad Laux is a Visiting Assistant Professor in the Industrial Technology Department at Purdue University in Anderson, Indiana. Chad teaches and conducts research in the areas of quality management systems and agriculture biotechnology. Additionally, Chad is coordinator of the Six Sigma Green Belt Certificate program for the College of Technology at Purdue. He is certified in the Six Sigma quality methodology from General Electric Co, Caterpillar Inc., and the American Society for Quality. Dr. Laux is a member of the National Association of Industrial Technology (NAIT) and American Society for Quaity (ASQ). Chad is also an active leader in the international arena. Dr. Laux serves as a delegate and Voting Member for the United States Technical Advisory Group for the creation for agriculture and food quality management standards. Some of the recent recognitions Dr. Laux has received include the Silvius-Wolansky Award for Outstanding Dissertation at Iowa State University in Industrial Technology. Honors include membership in Gamma Sigma Delta (GSD) Honor Society of Agriculture, and Epsilon Pi Tau (EPT) Honor Society in Technology.

\section{Edem Tetteh, Virginia State University}

Edem Tetteh received a Bachelor of Science degree in Industrial Technology and a Masters degree in Industrial Engineering from North Carolina Agricultural and Technical State University. He completed a Ph.D. in Industrial Technology at Purdue University. He is currently an Assistant Professor in the Department of Engineering and Technology at Virginia State University. He is a member of the Institute of Industrial Engineers (IIE) and The National Association of Industrial Technology (NAIT). Dr. Tetteh has received several awards which include Outstanding Academic Achievement Award, Who's Who among Universities and Colleges Award, and Best Ergonomics Paper Award at the IIE Conference in 2004 in Houston, TX.

\section{Carmen Caldwell, Virginia State University}

Ms. Caldwell is an undergraduate student and researcher at Virginia State University were she is pursuing a bachelor of science in Industrial and Logistics Technology. She is a Certified Quality Inspector from the American Society for Quality (ASQ). She is also an active member in the Society of Automotive Engineers (SAE). 


\title{
Reverse Curriculum Design of Lean Manufacturing for Distance \\ Education: ETD IT/IET Interest Group
}

\begin{abstract}
Due to globalization and recent trends, Lean manufacturing is an important area of competency for Industrial Technology students. As demographics of students change, the method of delivering curriculum changes as well. The development of a Lean manufacturing course to an on-line, asynchronous method from a traditional face-to-face method is discussed here. With the natural increase in knowledge in technology field, a reverse design curriculum model is utilized. A reverse design model begins with the end results of learning compared to a traditional curriculum model of 'covering' the material to ensure students have the competencies in knowledge and skills to prepare them for a global workplace.
\end{abstract}




\section{Introduction}

The impact of globalization over the last twenty years has resulted in a connection of much of the world economy. Organizations, and individuals, now collaborate and compete on a global scale through commerce ${ }^{1}$. For the individual to be able to successfully participate in a global economy, they should possess skills sets that result in an ability to understand and utilize technological change ${ }^{2}$. Central to this change has been the transformation in the manufacturing sector. Within manufacturing, the competitive strategy has been to create a system that utilizes the collective knowledge of the workforce tuned to efficient production. Called Lean Manufacturing or Lean Enterprise (Lean), the objective is to eliminate non-value added activities by focus on the external customer ${ }^{3}$. Developed in Japan, Lean has become a significant management strategy for the manufacturing company seeking to compete globally ${ }^{4}$. To maintain vitality in manufacturing, productivity in the United States requires individuals that can utilize such innovative ideas such as Lean ${ }^{2}$. A recent nationwide survey of manufacturing professionals puts Lean as the most important area of expertise for professionals to understand ${ }^{5}$. Lean has become an important topic in academic research engineering technology (ET) programs ${ }^{6}$. As colleges and universities adopt Lean into ET programs, the method of delivery varies as well. The changes in demographics of ET students require a variety of delivery methods ${ }^{7}$.

The traditional college student that is engaged full-time in coursework and living within a peer environment is giving way to a more unconventional model. The acceleration of an aging U.S. population has resulted in a wider demographic range of individuals identifying themselves as college students. Called non-traditional students, these individuals are often older, engaged in higher education in a part-time basis, and live outside an environment of higher learning. There are some benefits that a non-traditional student brings into the classroom. As older adults, nontraditional students often have a background in a professional career that traditional students lack. Also, non-traditional students are often working in an area that facilitates their learning inside the classroom. However, the main challenge of non-traditional education is the mode of delivery: students and their course instructor may be obliged to engage outside the classroom. One form of delivery is distance learning. Distance learning and distance education are interchangeable terms that commonly refer to a field of education that pertains to the design of advanced instructional systems used to deliver education remotely to students who are not physically present in the classroom ${ }^{8}$. The use of information technology and the internet allows the instructor and students to communicate asynchronously ${ }^{8}$. Asynchronous programming is an increasingly popular medium of higher education instruction ${ }^{9}$. Course technology, such as Blackboard ${ }^{\mathrm{TM}}$ and $\mathrm{WebCT}^{\mathrm{TM}}$ are used to supplement or deliver courses. This technology is appropriate for asynchronous delivery of coursework for traditional students, located on campuses and connecting with instructors through 'brick and mortar' classrooms, and nontraditional students, located afar and connecting with instructors at a distance ${ }^{10}$. The creation of a Lean course for online use to a varied (traditional and non-traditional) student body was done utilizing this framework. 


\section{Backwards Curriculum Design}

A 'backwards' curriculum design process was utilized to create an online Lean course for a diverse student body. Backwards curriculum design is a methodology to create curricula based on an industrial design based upon student achievement of desired learnings ${ }^{11}$. There are multiple stages of a backward design process. The first stage is to identify desired results or student learnings by asking essential questions of the body of knowledge to be taught: what should student know, understand, and be able to do? What are the enduring, or lasting, understandings that are desired of an instructional designer ${ }^{11}$ ? After identifying enduring understandings, the next stage is to determine acceptable evidence. The assessment of understandings is based upon the collective assessment of evidence needed to document understandings. The last stage is to plan and create the learning experiences and instruction ${ }^{11}$. Backwards design brings a number of benefits. By focusing on student outcomes, a backwards curriculum is learner focused. A curriculum written from the learner's point of view focuses on what the student will do, not the instructor $^{11}$. With students at the center of attention, this also assists the instructor in designing curriculum mindful of their student audience. Effectiveness of the curriculum is determined by student success in achieving the enduring understandings ${ }^{11}$. A primary characteristic is that students shape the instructional work ${ }^{11}$. These features make backward design desirable to ET faculty in developing coursework.

\section{Lean Course Competencies}

Technology faculty must respond to the requirements of student assessment and ensure that graduates of an ET program meet both the expectations and standards of the institution, and other stakeholders, such as private industry ${ }^{12}$. To meet expectations of various stakeholders, accreditation to a nationally recognized body, such as TAC-ABET, may be completed by ET programs ${ }^{13}$. Accreditation criteria of ABET places emphasis on learner-centered instruction and measured learning ${ }^{14,15}$. Learner centered instruction and measured learning are tenants of a backwards curriculum design. A backwards design process is essential for the creation of a distance education course ${ }^{16}$. By utilizing learner understandings, backwards curriculum design can provide advance organization and planning for effective delivery ${ }^{16}$. The creation of an online Lean course was based on the accreditation idea of meeting various stakeholder expectations through a backwards design process.

The creation of the online Lean course was based on the creation of enduring understandings. Instructional design and assessment was based upon these competencies. The competencies were created based upon faculty expertise, faculty industry experience, and external industry identification of proficiency. Both course designers have experience in teaching Lean as an undergraduate course. In addition, the designers have industry background that makes the process of creating enduring understandings relevant. Finally, the enduring understandings were reconciled with Society of Manufacturing Engineers (SME) competencies (appropriate to an introduction to Lean course) of SME Lean body of knowledge certification ${ }^{17}$. As the leading society for manufacturing professionals, SME reference is appropriate for external industry recognition ${ }^{18}$. The enduring understandings were incorporated into a course syllabus for assessment of the research study. 


\section{Assessment}

Utilization of a syllabus for assessment of student perceptions is appropriate. As the primary written communication between the instructor and students, utilizing the syllabus as a medium for student assessment is suitable ${ }^{19}$. It is also suitable for describing the online, Lean course since a course syllabus has been previously been utilized for student assessment of course understandings ${ }^{19,20}$. Utilizing a syllabus also clarifies learner expectations of course material and align instructor and student perceptions of the most important course understandings; a tenant of backwards design ${ }^{11,19}$. Feedback from students through a survey of a Lean manufacturing syllabus will aid further development of the course for continuous improvement of distance delivery $^{21}$.

The following research questions were explored:

1. Do students' perception of the syllabi differed based on the university they attend?

2. Do students' perception of the syllabi differed based on their enrollment status such as part time or full time?

3. Is there a strong correlation between ownership of learning, promotion online collaboration, competency building with problem solving ability, and critical thinking as the achievement of the course outcome?

\section{Methodology}

\section{Survey Instrument}

A questionnaire consisting of 31 questions chosen from a catalog of validated course evaluation questions pertaining to the selected topics and took approximately five to ten minutes to complete $^{22}$. It included questions about the following: basic demographic information, university attended, major study area, highest level of education completed, enrollment status, frequency of computer use and questions based on four functions of a backwards curriculum design for distance education. The four functions are the following: students' ownership of learning, promotion of students' online collaboration, competency building with problem solving ability, and critical thinking as the achievement of the course outcome described in Table 1.

\begin{tabular}{|l|l|l|}
\hline Function & Facet of Understanding & Definition \\
\hline Function 1 & $\begin{array}{l}\text { Students ownership of } \\
\text { learning }\end{array}$ & $\begin{array}{l}\text { Student's explain through knowledgeable and } \\
\text { justified accounts of ideas, events, and actions }\end{array}$ \\
\hline Function 2 & $\begin{array}{l}\text { Promotion of students' } \\
\text { online collaboration }\end{array}$ & $\begin{array}{l}\text { Students' ability to get inside another student's } \\
\text { view and understanding }\end{array}$ \\
\hline Function 3 & $\begin{array}{l}\text { Competency building } \\
\text { with problem solving } \\
\text { ability }\end{array}$ & $\begin{array}{l}\text { Students uses knowledge in authentic situations } \\
\text { and understand background of that knowledge }\end{array}$ \\
\hline Function 4 & $\begin{array}{l}\text { Critical thinking as the } \\
\text { achievement of the }\end{array}$ & $\begin{array}{l}\text { Students have self-knowledge to know one's } \\
\text { ignorance and patterns of thought and action }\end{array}$ \\
\hline
\end{tabular}


Table 1: Definitions of the Functions of a Reverse Curriculum Design

The task was designed to investigate students' perceptions about a reverse curriculum designed Lean course created in a collaborative environment between University A and University B. Three types of syllabi: traditional (live) delivery, current distance delivery, and a distance delivery based upon backwards design were used in the study. The participants were assigned to one of the three possible groups based upon which syllabus they evaluated. Each syllabus type was sent randomly to each participant along the survey for his/her evaluation before completing the survey. The participants' perception was determined by the series of questions each using a Lickert scale from one (strongly agree) to five (strongly disagree). The participants were allowed to take the survey, even if they had never taken a distance education course in the past. The researchers used Qualtrics, survey software, to construct the survey along with a consent form.

\section{Study Participants}

The population of participants in this study was approximately 41 students (Table 2) registered in Engineering and Technology programs at University A and University B, two public university locates respectively on the Southeast and Northwest of the United States of America. University A is a fairly small school with less than five thousand students, less than 300 faculty and staff, and less than fifty courses offered online. University B is a large university with more than fiftythousand students and more than three-hundred courses offered online every semester. Sixty-four percent (64\%) of the respondents are attending University A and 36\% University B. Seventyeight percent $(78 \%)$ were male and $22 \%$ twenty-two percent were female. When asked about their age, $70.7 \%$ seventy point seventy of the respondents were between 18 and 25 years, $4.9 \%$ were between 26 and 34 years of age and $24 \%$ were 35 and over. Students were classified as part time (less than 12 credits) and full time (more than 12 credits) at $24.4 \%$ part time and $75.6 \%$ full time respectively. When asked about their highest level of education, 39\% of the respondents said they are currently classified as freshman, $29.3 \%$ are considered sophomore, $17 \%$ as junior, 12.2 as senior and $2.4 \%$ as master's degree students. There were no students classified as doctoral degree students, even though the option was provided. When questioned about their frequency of use of computers, $80 \%$ attested that they use computers several times in a day, $14 \%$ use computers few times in a day and $4.9 \%$ percent said once a day. No participants selected the options of using computer once a week or very rarely. Each participant was required to sign an informed consent form prior to participating in the study. The study protocol was approved by both University A and University B Internal Review Board (IRB) where the study took place.

\section{Procedure}

A mass email was sent to the students from both schools inviting them to participate in the study. Before beginning the survey each participant received a briefing on the nature, objectives, and potential risks of the study. Next, the participants were asked to sign a consent form online. Students could leave the survey at any time. If a student object to the consent form, a thank you notice appeared on the screen, and they were prompted to leave the survey. If the participant accepted, the participant was taken directly to the survey main page. The participant received 
instructions to become familiar with the tasks of the survey. Upon the notification to start, they began the tasks. A place for comments was placed at the end of the survey. Once the survey was completed, a thank you e-mail was sent to the participant.

\section{Results}

\section{Comparison of University A and University B students' satisfaction of the syllabi.}

To answer our first research question, we examine the two groups of students used in the study. University A students rated the reverse curriculum design syllabus $11.1 \%$ compared to the traditional (live) delivery $18.5 \%$ and current distance delivery syllabi $70.4 \%$. Students from University B, on the other hand, gave the same rate to the distance delivery based upon backwards design, $23.7 \%$ and to the traditional (live) delivery 33.4\%. Current distance delivery syllabi received a $42.9 \%$ approval from the students. The two groups did not differ on their dissatisfaction of the reverse curriculum design syllabus which received the lowest rating in the case of both group of students.

\section{Comparison of students' satisfaction of a syllabus design based on their enrollment status such as part time or full time.}

To examine our second question, we considered the students enrollment status to examine its extent on student satisfaction. Out of the two enrollment status considered in the study, the full time students viewed distance delivery based upon backwards design to be the least satisfying design $9.7 \%$, compared to the traditional (live) delivery $67.7 \%$ and current distance delivery syllabi $22.6 \%$. The students with a part time status gave delivery based upon backwards design to be the most satisfying design along with the current distance delivery syllabi, followed by the traditional (live) delivery $40 \%$.

\section{Student's importance of four functions of a lean course syllabus based on reverse curriculum design principles.}

A statistical software program, SAS version 9.1, was employed in model testing. A correlation was conducted to measure the strength of any relationship between the four functions of the syllabus designed based on reverse curriculum principles. Correlations of the predictor variables with the predicted variable were reported as Pearson correlation coefficients by the linear multiple regression analysis (Table 1).

From the table it can be seen that the largest coefficient occurred between Function 1 and Function $3(0.86038 \mathrm{p}=<.0001)$. It was expected that the two functions will be highly correlated showing that the analysis would provide a meaningfully results. The next highest was $(0.83917$; $\mathrm{P}=<.0001$ ) and occurred between Function 1 and 4 . On the other hand, the weakest correlation occurred between Function 2 and Function 3 (0.53428; $\mathrm{p}=0.0003)$, following by function 1 and 2 (0.59986; $\mathrm{p}<.0001)$. 


\begin{tabular}{|l|l|l|l|l|}
\hline & Function 1 & Function 2 & Function 3 & Function 4 \\
\hline Function 1 & & & & \\
\hline Function 2 & $\begin{array}{l}0.59986 \\
<.0001\end{array}$ & & & \\
\hline Function 3 & $\begin{array}{l}0.86038 \\
<.0001\end{array}$ & $\begin{array}{l}0.53428 \\
0.0003\end{array}$ & & \\
\hline Function 4 & $\begin{array}{l}0.83917 \\
<.0001\end{array}$ & $\begin{array}{l}0.68334 \\
<.0001\end{array}$ & 0.83393 & \\
& $<.0001$ & \\
\hline
\end{tabular}

Table1. Pearson Correlation Value P-Value

\section{Discussion}

This study resulted in a satisfaction rating of syllabi, regardless of how the syllabi were designed. The syllabi were based on distance delivery created through a backwards design, traditional (live) delivery, and current distance delivery. Four functions critical to a good syllabus were used to test each design. University A and University B students favored the distance delivery based upon a backwards design least. This can be explained by the fact that the students from both schools are not familiar with the backwards design concept through distance delivery. Asking students to rate their satisfaction with the document is accessing their familiarity of the document. The design of a curriculum process backwards is a faculty function. This study shows that it currently resides a function of faculty.

There remains a difference in students rating between the traditional (live) delivery and the current distance delivery design. University A selected the traditional (live) design to be the best design, while University B students gave the highest rate to the current distance delivery syllabus. This can be explained by the level of Distance Education (DE) delivery level at both universities. While University B is a mature university in DE and offers many courses online, The DE effort at University A is very recent and many of the its students have never taken online course or are in their first semester experience. Their preference goes to the traditional (live) whereas University B students preferred the current distance delivery syllabus.

The full time students, when asked to rate the three syllabi, gave the highest rate to the current distance delivery design and the part time students rated the same design the lowest. The other two types gave a split opinion. This can be explained by the fact that the students attending school full time are younger, selecting more online courses, and are dictating their preference for the current distant delivery design. In contrast, part time students are older and are more familiar with more traditional delivery.

The correlation analysis conducted in the study showed the strongest correlation between students' ownership of learning and competency building with problem solving ability. A student who explains through knowledgeable and justified accounts of ideas, events, and actions will ultimately develop a problem solving through critical thinking ability. An emphasis of one of these two functions will ultimately uncover the others. A good syllabus will emphasis typically one, not necessary both. A backwards curriculum process, designed to 'uncover' student, should focus on the student's view of knowledge more sophisticated by the student's actions, events, 
and ideas. Thus, a syllabus devised from the functions of reverse design, should drive the rest of curriculum development.

\section{Conclusions}

In recent years, there has been more attention given to curriculum design because of the complexity and the importance given to the skills that the students need to gain. This study assessed three types of syllabi using students' perception. The results of the study showed that a profound understanding of the elements of a new type of syllabus is required to familiarize the students to the material before its introduction. Furthermore, it was shown that students with different backgrounds tend to favor different types of curriculum design.

However, because of the limitations of this research, such as the use of a small number of participants in the survey and the unavailability of other types of schools such as private or community colleges, readers should be cautious in making generalizations from the study findings. Future research can focus on using a survey to assess students' perception, but instructors' as well from many types of schools.

\section{Bibliography}

1. The World is Flat: A Brief History of the Twenty-First Century, Friedman, Thomas L., Farrar, Straus \& Giroux, 2006.

2. Rising Above the Gathering Storm: Energizing and Employing America for a Brighter Economic Future, The National Academies Press, 2006.

3. Lean Thinking : Banish Waste and Create Wealth in Your Corporation, Womack, James P., and Jones, Daniel T., Simon and Schuster, 1996.

4. Toyota Production System. Ohno, Taiichi, Productivity Press, 1987.

5. Callahan, R. Neal, Jones, Martin, and Smith, Rathel R., "Developing Maximum Career Potential in Manufacturing Technology Curricula.” Journal of Industrial Technology, 2008, Vol. 24, pp. 1-8.

6. Scachitti, Susan, Workman-Germann, Jamie, Stephens, Matthew P., Annaji Sharma, Ammu, and Szromba, Richard. "Adding Lean and Six Sigma to Industrial Engineering Technology Programs: Does this Constitute a Change in Curriculum?" Proceedings of the American Society for Engineering Educatioon Conference and Exposition, June 2008.

7. Burgess, Lesta A., "WebCT as an E-learning Tool: A Study of Technology Students' Perceptions." Journal of Technology Education, 2003, Vol. 15, No. 1, pp. 1-9.

8. Mehrabian, Ali, “Application of Technology in Course Transformation from Live to Distance Learning." The Technology Interface, 2007, Vol. 8, No. 1, pp. 1-7.

9. Freeman, Steven A., and Field, Dennis W., "Student Perceptions of Web-Based Supplemental Instruction." The Journal of Technology Studies. 2004, Vol. 30, No. 4, pp. 25-33.

10. Zapalska, Alina, Shao, Lawrence P., and Shao, Dale H., "Evaluating the Effectiveness of WebCT using Student Feedback." Academy of Educational Leadership Journal, 2003, Vol. 7, No. 3, pp. 91-101.

11. Understanding by Design. Wiggins, Grant, and McTighe, Jay, Merrill Prentice Hall, 2001.

12. Field, Dennis W., Freeman, Steven A., and Dyrenfurth, Michael J., "Holistic Assessment of Students in Undergraduate Industrial Technology Programs." The Journal of Technology Studies, 2004, Vol. 30, No. 4, pp. 78-85.

13. ABET, "The Basics: Accreditation Assures Quality.”, retrieved March 2009 from http://www.abet.org/the basics.shtml.

14. 2009-2010 Criteria for Accrediting Engineering Technology Programs, TAC-ABET, ABET Inc., 2008.

15. Fuehne, Joesph P., "Creating Multiple Assessments from Classroom Assignments." The Technology Interface. 2007, Vol. 8, No. 1, pp. 1-18.

16. Torgrude, Marcia, Anderson, Rose, and O’Connor, Brian, 2001, "Backward Curriculum Design and Its Relevance to Distance Education.” retrieved March 2009 from http://staff.tie.net/mtorgrude/Masters/ curriculum/Backward\%20design.pdf

17. Society of Manufacturing Engineers, March 2006. "Lean Certification Body of Knowledge Rubric." retrieved March 2009 from http://www.sme.org/downloads/cert/lean/BOK.pdf 
18. Society of Manufacturing Engineers, "SME History", retrieved March 2009 from http://www.sme.org/cgibin/getsmepg.pl?/html/history.htm\&\&\&SME\&

19. Garavalia, Linda S., Hummel, John H., Wiley, Larry P., \& Huitt, William G., "Constructing the Course Syllabus: Faculty and Student Perceptions of Important Syllabus Components." Journal on Excellence in College Teaching, 1999, Vol. 10, No. 1, pp. 5-21.

20. Matejka, Ken, and Kurke, Lance B., "Designing a Great Syllabus." College Teaching, 1994, Vol. 2, No. 3, pp. 115-118.

21. The Course Syllabus: A Learning-Centered Approach. Grunert, Judith, Anker Publishing. 1997.

22. Purdue Center for Instructional Excellence, 2008, "Purdue Instructor Course Evaluation Service Item Catalog", retrieved March 2009 from http://www.cie.purdue.edu/search/files/catalog.pdf 